\title{
Effect of heat treatment on strength and abrasive wear behaviour of Al6061-SiC $\mathrm{p}$ composites
}

\author{
N R PRABHU SWAMY ${ }^{\dagger}$, C S RAMESH ${ }^{\dagger \dagger}$ and T CHANDRASHEKAR* \\ Department of Mechanical and Production Engineering, Velammal Engineering College, Chennai 600 066, India \\ ${ }^{\dagger}$ Department of Mechanical Engineering, BMS College of Engineering, Bangalore 560 004, India \\ ${ }^{\dagger \dagger}$ Department of Mechanical Engineering, PES Institute of Technology, Bangalore 560 085, India
}

MS received 15 November 2008; revised 22 January 2009

\begin{abstract}
In recent years, aluminum alloy based metal matrix composites (MMC) are gaining importance in several aerospace and automobile applications. Aluminum 6061 has been used as matrix material owing to its excellent mechanical properties coupled with good formability and its wide applications in industrial sector. Addition of $\mathrm{SiC}_{\mathrm{p}}$ as reinforcement in Al6061 alloy system improves its hardness, tensile strength and wear resistance. In the present investigation $\mathrm{Al6061}-\mathrm{SiC}_{\mathrm{p}}$ composites was fabricated by liquid metallurgy route with percentages of $\mathrm{SiC}_{\mathrm{p}}$ varying from $4 \mathrm{wt} \%$ to $10 \mathrm{wt} \%$ in steps of $2 \mathrm{wt} \%$. The cast matrix alloy and its composites have been subjected to solutionizing treatment at a temperature of $530^{\circ} \mathrm{C}$ for $1 \mathrm{~h}$ followed by quenching in different media such as air, water and ice. The quenched samples are then subjected to both natural and artificial ageing. Microstructural studies have been carried out to understand the nature of structure. Mechanical properties such as microhardness, tensile strength, and abrasive wear tests have been conducted both on matrix Al6061 and Al6061-SiC composites before and after heat treatment. However, under identical heat treatment conditions, adopted Al6061-SiC $\mathrm{p}_{\mathrm{p}}$ composites exhibited better microhardness and tensile strength reduced wear loss when compared with Al matrix alloy.
\end{abstract}

Keywords. Metal matrix composite; solutionizing; artificial aging; microhardness; tensile strength; abrasive wear.

\section{Introduction}

Metal matrix composites (MMCs) are gaining wide spread popularity in several technological fields owing to its improved mechanical properties when compared with conventional metals/alloys (Ramesh 1988; Ray 1993; Surappa 2003). Among the several categories of MMCs, Al based composites are finding wide spread acceptance especially in applications where weight and strength are of prime concern. Presently, Al alloy based metal matrix composites are being used as candidate materials in several applications such as pistons, pushrods, cylinder liners and brake dics etc. (Anwar Khan et al 2002; Surappa 2003). In recent years, among all the $\mathrm{Al}$ alloys, Al6061 is gaining much popularity as a matrix material to prepare MMCs owing to its excellent mechanical properties and good corrosion resistance (Ramesh et al 2005). In addition, Al6061 alloy is heat treatable, and as a result further increase in strength can be expected (Appendino et al 1991; Salvo and Surey 1994; Gupta and Surappa 1995; Anwar Khan et al 2002). However, the major focus is on processing and characterization of $\mathrm{Al}$ based composites (Appendino et al 1991; Pramila Bai et al 1992; Doel and

\footnotetext{
*Author for correspondence (chandrashekarthi@yahoo.com)
}

Bowen 1996; Gui et al 2000). Although the synergetic effect of heat treatment and the type of reinforcement plays a dominant role in dictating the final mechanical properties of composites, meager information is available, pertaining to the heat treatment of Al based composites. In light of the above, the present investigation is aimed at studying in detail the effect of quenching media and the ageing duration on the mechanical properties of heat treatable cast $\mathrm{Al} 6061-\mathrm{SiC}_{\mathrm{p}}$ composites.

\section{Experimental}

A liquid metallurgy route has been adopted to fabricate the cast composites. Al6061 has been chosen as matrix alloy. Preheated $\mathrm{SiC}_{\mathrm{p}}$ of size 10-20 $\mu \mathrm{m}$ was introduced into the vortex of the effectively degassed Al6061 molten alloy. The molten alloy was stirred for a duration of $10 \mathrm{~min}$ using a mechanical stirrer possessing ceramic coated steel impeller. The speed of the stirrer was maintained at $400 \mathrm{rpm}$. The melt at $710^{\circ} \mathrm{C}$ was poured into the cast iron molds. The addition of the silicon carbide particles in the matrix alloy was varied from $4-10 \mathrm{wt} \%$ in steps of $2 \mathrm{wt} \%$.

The cast composites and the base Al6061 alloy were subjected to solutionizing at a temperature of $530^{\circ} \mathrm{C}$ for a duration of $1 \mathrm{~h}$ and then quenched in three different 


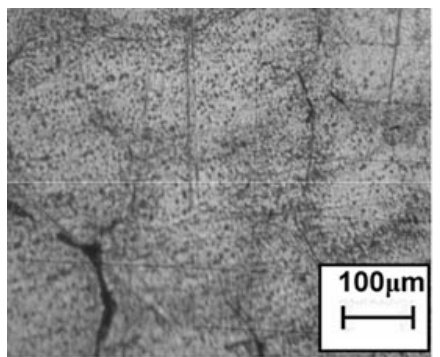

(a) Al6061 alloy

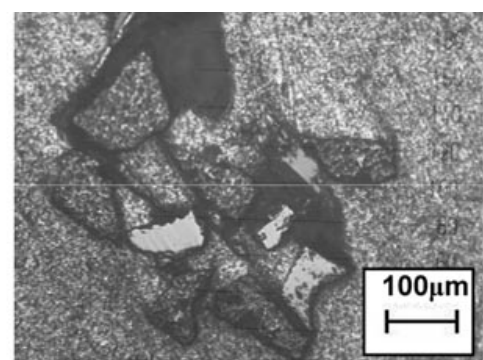

(b) $\mathrm{Al} 6061-4 \mathrm{wt} \% \mathrm{SiC}$

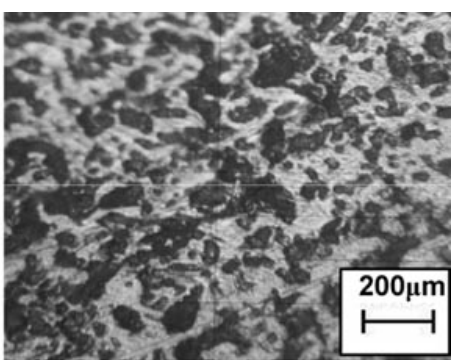

(c) $\mathrm{Al} 6061-6 \mathrm{wt} \% \mathrm{SiC}$

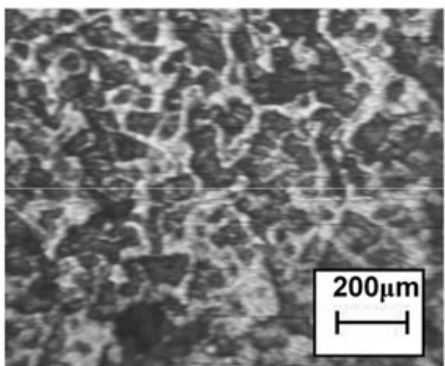

(d) $\mathrm{Al} 6061-8 \mathrm{wt} \% \mathrm{SiC}$

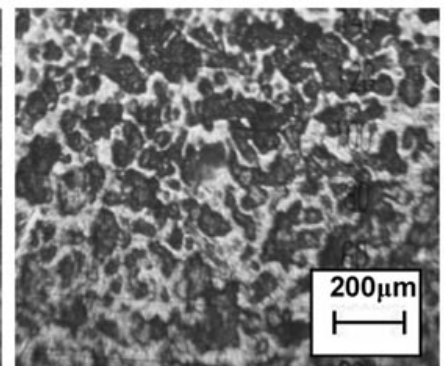

(e) $\mathrm{Al} 6061-10 \mathrm{wt} \% \mathrm{SiC}$

Figure 1. Optical microphotographs of base A16061 alloy and $\mathrm{A} 16061-\mathrm{SiC}_{\mathrm{p}}$ composites at 4, 6, 8 and $10 \mathrm{wt} \% \mathrm{SiC}_{\mathrm{p}}$.

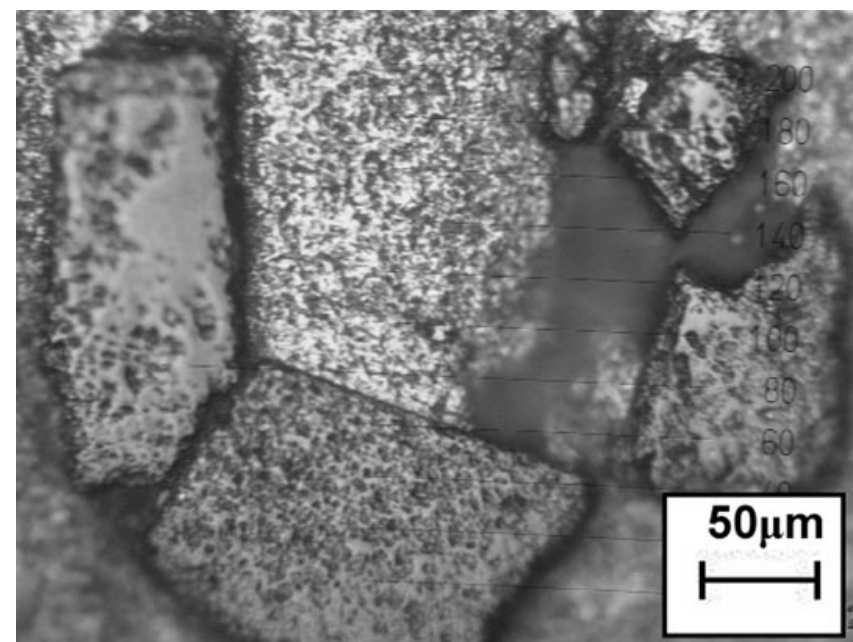

Figure 2. Optical micrograph of Al6061-4 wt $\% \mathrm{SiC}$ indicating good bond between the matrix alloy and $\mathrm{SiC}_{\mathrm{p}}$.

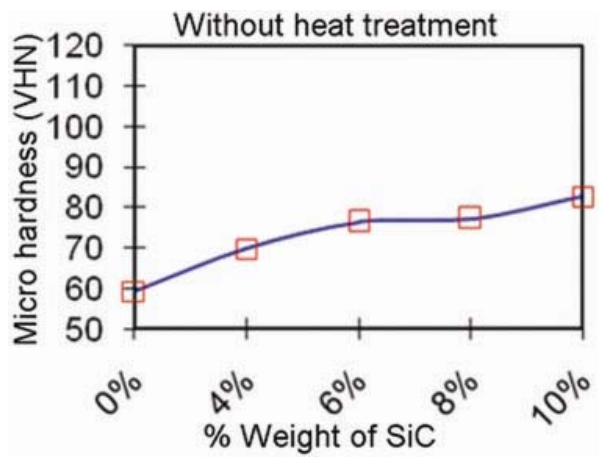

Figure 3. Variation of microhardness of A16061- $\mathrm{SiC}_{\mathrm{p}}$ composites with increase of $\mathrm{SiC}_{\mathrm{p}}$ content before heat treatment. quenching media viz. air, water and ice. Artificial ageing was carried out at $175^{\circ} \mathrm{C}$ for a duration of $4-10 \mathrm{~h}$ in steps of $2 \mathrm{~h}$. Metallographic, hardness, tensile strength and wear tests were carried out on both unheat treated and heat treated samples. Hardness measurements were carried out on the castings using Shimadzu Microhardness tester using a load of $1 \mathrm{~N}$ for a period of $10 \mathrm{~s}$. Tensile tests were conducted on both base Al6061 alloy and its composites for samples heat treated with water and ice medium. The abrasive wear test was conducted for a duration of $15 \mathrm{~min}$ for three grades of silicon carbide wheels viz. coarser, medium and fine wheel for varying loads from $5 \mathrm{~N}$ to $20 \mathrm{~N}$ in steps of $5 \mathrm{~N}$.

\section{Results and discussion}

\subsection{Microstructure}

The optical micrograph of the cast Al6061 and Al6061$\mathrm{SiC}_{\mathrm{p}}$ composites are shown in figure 1. The micrographs clearly indicate the evidence of minimal porosity in both the $\mathrm{Al}$ alloy and the $\mathrm{Al} 6061-\mathrm{SiC}_{\mathrm{p}}$ composites. The distribution of $\mathrm{SiC}_{\mathrm{p}}$ in a matrix alloy is fairly uniform. Further the microphotographs reveal an excellent bond between the matrix alloy and the reinforcement particles (figure 2).

\subsection{Hardness}

The variation of microhardness with increased content of $\mathrm{SiC}_{\mathrm{p}}$ in the matrix Al6061 in as cast condition without heat treatment is shown in figure 3 . It is observed that 

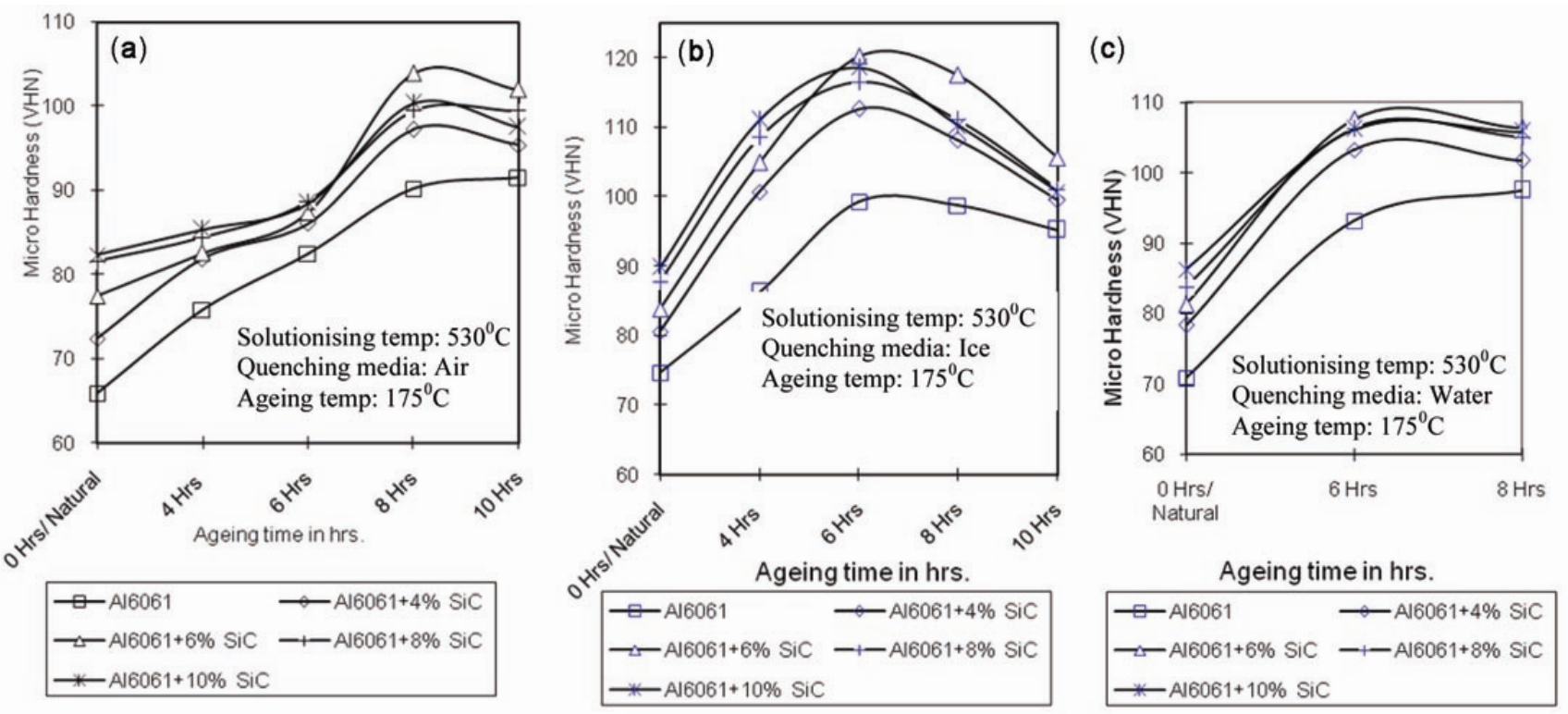

Figure 4. Variation of microhardness with increase in ageing time for A16061 and $\mathrm{Al} 6061-\mathrm{SiC}_{\mathrm{p}}$ composites under different heat treatment conditions.

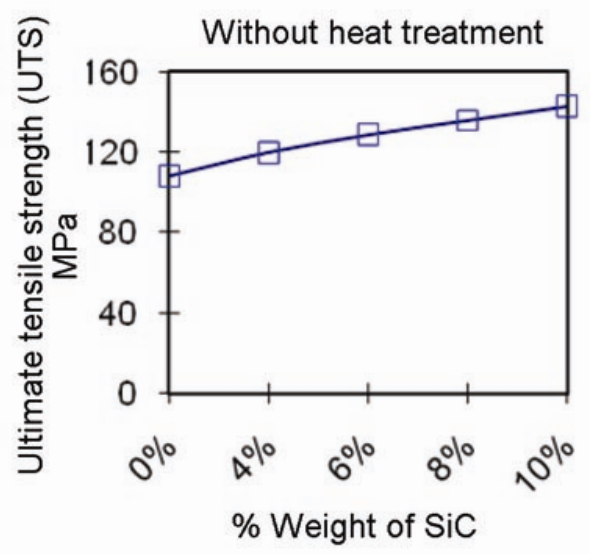

Figure 5. Variation of UTS of $\mathrm{Al} 6061$ and $\mathrm{A} 16061-\mathrm{SiC}_{\mathrm{p}}$ composites with increased content of $\mathrm{SiC}_{\mathrm{p}}$.

with increased content of $\mathrm{SiC}_{\mathrm{p}}$ in the matrix alloy, there is a significant improvement in the microhardness of the composites. An improvement of around 39\% is observed in $\mathrm{Al6061}-10 \mathrm{wt} \% \mathrm{SiC}_{\mathrm{p}}$ composites when compared with the unreinforced Al6061 matrix alloy. This trend is similar to the result of other researchers (Sahin and Acilar 2003).

The variation of microhardness under heat treatment conditions are shown in figure 4 . Heat treatment has a profound influence on the hardness of the matrix alloy as well as its composites. For a solutionizing temperature of $530^{\circ} \mathrm{C}$, solutionizing duration of $1 \mathrm{~h}$, ageing temperature of $175^{\circ} \mathrm{C}$, quenching media and ageing duration significantly alters the microhardness of both the matrix alloy and its composites. The maximum hardness was observed

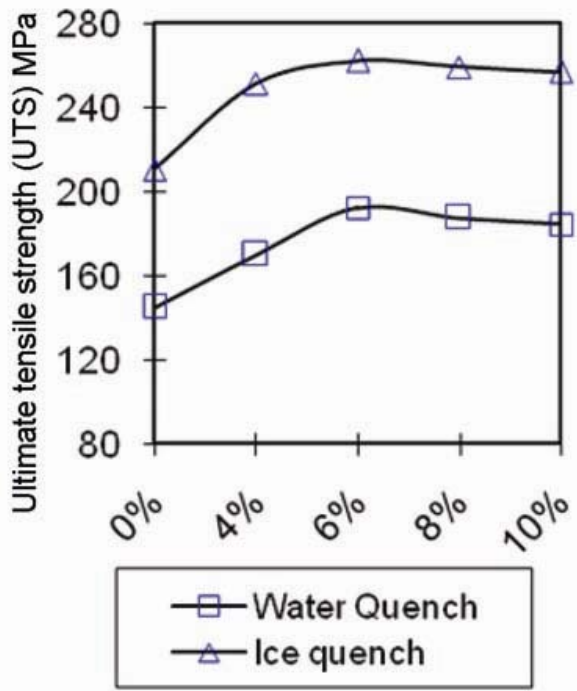

Figure 6. Variation of UTS with increased content of $\mathrm{SiC}_{\mathrm{p}}$ in Al6061 alloy under different heat treatment conditions.

for both the matrix alloy and the studied composites for ageing duration of $6 \mathrm{~h}$ when the quenching media was ice and water, while the maximum hardness for the matrix alloy and its composites was achieved only after $8 \mathrm{~h}$ of ageing on air quenching. In all the quenching media, and under all ageing times studied, composites exhibited higher hardness when compared with the matrix alloy.

Ageing of matrix alloy and its composites for a duration of $6 \mathrm{~h}$ at a temperature of $175^{\circ} \mathrm{C}$ upon ice quench after solutionizing results in obtaining maximum hardness of the matrix alloy and its composites. Ice quenching and ageing for $6 \mathrm{~h}$, the matrix Al6061 alloy exhibited a 
maximum improvement in hardness of around $67 \%$, while Al6061-10 wt\%SiC composites exhibited a maximum improvement in hardness of around $44 \%$. On water quenching and ageing for $6 \mathrm{~h}$, the matrix Al6061 alloy exhibited a maximum improvement of microhardness of around 57\%, while Al6061-10wt\%SiC composites exhibited a maximum improvement in hardness of around $28 \%$. On air quenching and ageing for $8 \mathrm{~h}$, the matrix Al6061 alloy exhibited a maximum improvement in hardness of around 52\%, while Al6061-10wt\% SiC composites exhibited a maximum improvement in hardness of around $21 \%$.

\subsection{Tensile strength}

The variation of ultimate tensile strength (UTS) with increased \% of $\mathrm{SiC}_{\mathrm{p}}$ in matrix alloy Al6061 is shown in figure 5. This trend is similar to observation made by other researchers (Robi et al 1996). Al6061-10 wt\% SiC composites exhibited the highest UTS of $143 \mathrm{MPa}$, while the matrix alloy Al6061 exhibited an UTS value of $108 \mathrm{MPa}$ in as cast unheat treated condition. The improved UTS of composites can be attributed to the fact that increased content of $\mathrm{SiC}_{\mathrm{p}}$ increases the hardness of the composites, which in turn enhances the tensile strength of the composites. The good bond exhibited as discussed in the previous section also promotes the improvement of tensile strength of composites.

The variation of UTS under different heat treatment conditions is shown in figure 6 . Heat treatment has a significant effect on the UTS of matrix alloy and its composites. For a solutionizing temperature of $525^{\circ} \mathrm{C}$, solutionizing duration of $1 \mathrm{~h}$, ageing temperature of $175^{\circ} \mathrm{C}$, ageing duration of $6 \mathrm{~h}$, the quenching media significantly alters the UTS of both the matrix alloy and its composites. As evidenced in figure 6 the maximum UTS was observed, for both the matrix alloy and the composites when the quenching media was ice.

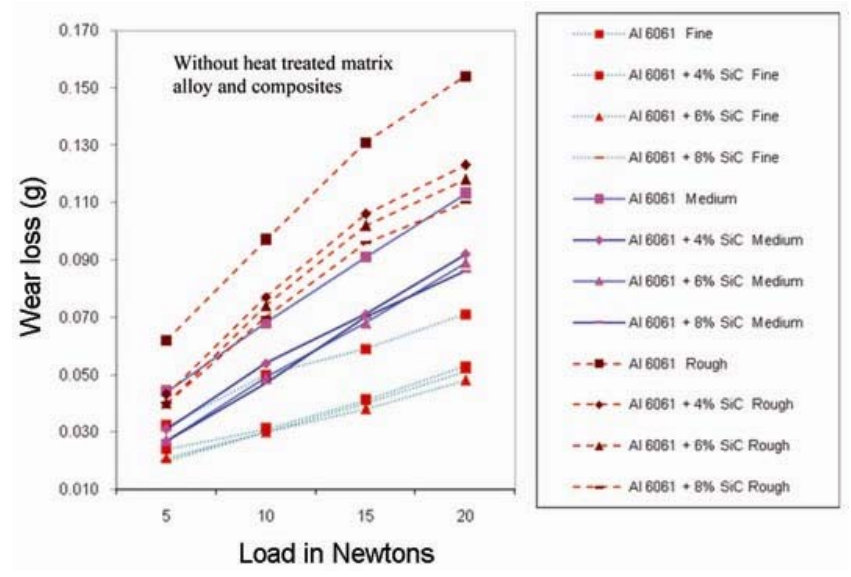

Figure 7. Variation of abrasive wear loss with increase in loads for different grades of abrasive wheels
The maximum UTS of $210 \mathrm{MPa}$ for the matrix alloy and the value of $257 \mathrm{MPa}$ for the Al6061-10 wt\% $\mathrm{SiC}$ has been observed on ice quenching. An improvement of around $79 \%$ in UTS values has been observed for Al6061-10 wt\%SiC, while the matrix alloy exhibited nearly $94 \%$ improvement in UTS on heat treatment. This marked improvement in tensile strength of both Al6061 alloy and its composites studied on heat treatment can be attributed to larger extent of formation of intermetallic precipitates which act as the points of obstacles for pinning down the dislocations. This phenomena of multiplication of dislocations curtails the mobility of dislocations, thereby reducing the extent of plastic deformation. This leads to significant improvement in UTS.

\subsection{Abrasive wear}

The variation of abrasive wear loss of both the unreinforced Al6061 and Al6061-SiC composites under different loads and different grades of abrasive for unheat treated condition is shown in figure 7 . It is observed that the amount of reinforcement in the matrix alloy and the grades of the abrasive wheels have profound influence on the abrasive wear behaviour of matrix alloy and its composites at a given load. Increased content of $\mathrm{SiC}_{\mathrm{p}}$ in the matrix alloy enhances the abrasive wear resistance of composites which can be attributed to the fact that $\mathrm{SiC}$ itself being hard can combat the abrasion, thereby resulting in lower material removal. Higher the hardness of composites, better will be its abrasion resistance. For a given load, the abrasive wear tends to be higher for both the matrix alloy and its composites while rubbing against a coarser abrasive silicon carbide wheel. This increased material removal can be attributed to the fact that coarser silicon carbide grains of the abrasive wheel will tend to dig in and plough out the material sideways. This phenomena results in huge material removal. The lowest wear loss for the matrix alloy and the composites have been observed when fine grades of abrasive wheel have been used. This can be explained on the grounds that the fine grade wheel having a closed type of structure results in more of scratching rather than ploughing out the material. This phenomena leads to a very marginal material removal. Under identical test conditions, composites possess better abrasive wear resistance when compared with matrix alloy.

The heat treatment of matrix alloy and its composites has a significant effect on the abrasive wear behaviour of matrix alloy and its composites as shown in figure 8 . For a given load and grades of abrasive wheel used, ice as quenching media has resulted in the least abrasive wear loss when compared to without heat treated matrix alloy and its composites. However, composites possessed the lowest abrasive loss when compared to matrix alloy. The improved abrasion wear resistance after heat treatment 

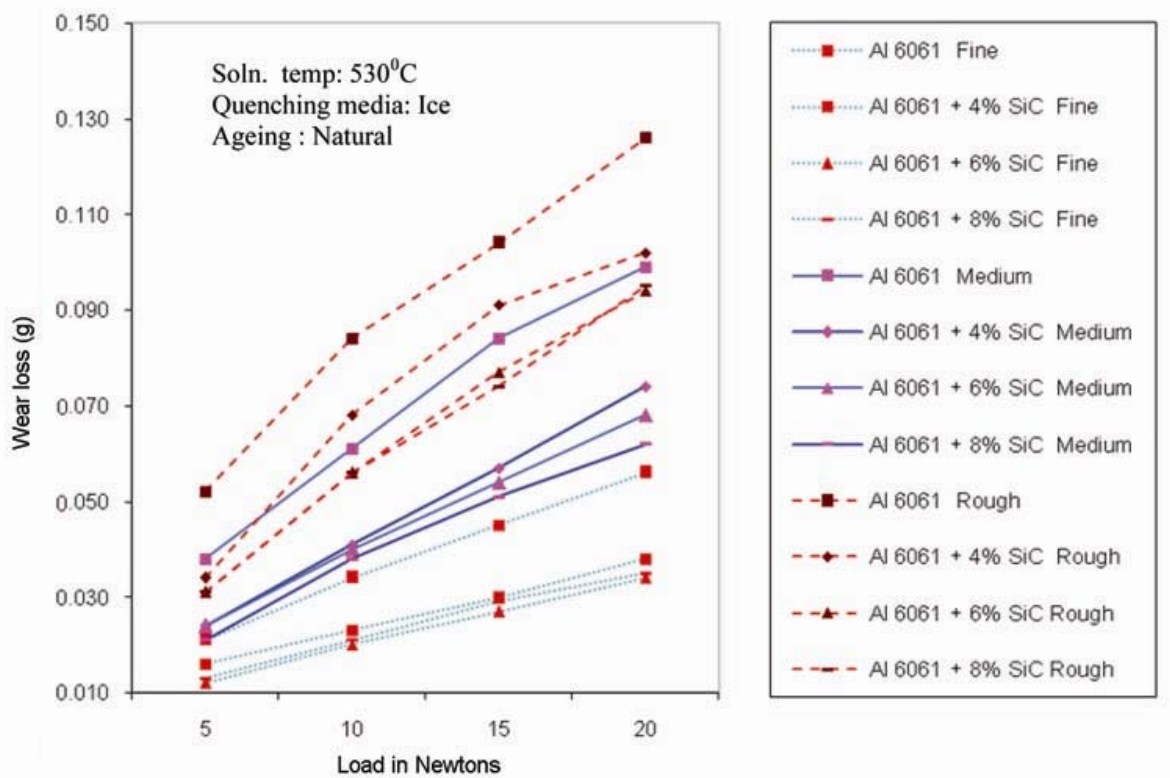

(a) Natural ageing

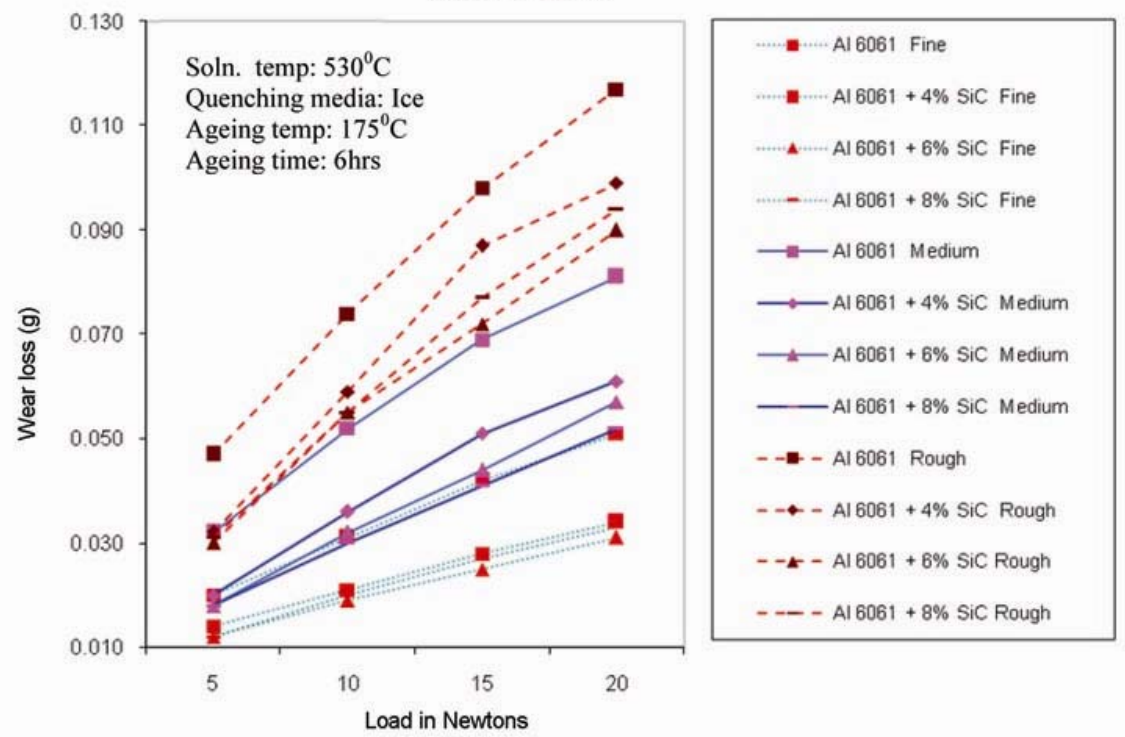

(b) Artificial ageing

Figure 8. Effect of different ageing conditions on abrasive wear loss of matrix alloy and its composites for different grades of abrasive wheels.

can be attributed to further enhancement of hardness on heat treatment.

\section{Conclusions}

Microstructural studies clearly reveal a uniform distribution of $\mathrm{SiC}_{\mathrm{p}}$ in the matrix alloy with an excellent bond between the matrix alloy and reinforcement.

Microhardness of composites increased significantly with increased content of $\mathrm{SiC}_{\mathrm{p}}$. Heat treatment has a significant effect on microhardness of Al6061 matrix alloy and its composites. Ice quenching followed by artificial ageing for $6 \mathrm{~h}$ resulted in maximum hardness of matrix alloy and its composites.

Tensile strength of composites increased significantly with increased content of $\mathrm{SiC}_{\mathrm{p}}$. Heat treatment has a significant effect on UTS of matrix alloy and its composites. Ice quenching followed by artificial ageing for $6 \mathrm{~h}$ resulted in maximum UTS of Al6061 matrix alloy and Al6061- $\mathrm{SiC}_{\mathrm{p}}$ composites.

Adhesive wear loss of composites decreases, with the increase in content of $\mathrm{SiC}_{\mathrm{p}}$ in matrix alloy under identical test condition. Heat treatment has a profound effect on adhesive wear behaviour of matrix alloy and its composites. 


\section{References}

Anwar Khan A R, Ramesh C S and Ramachandra A 2002 Heat treatment of Al6061-SiC composites, Proceedings of the int. conf. on manufacturing (Dhaka: ICM) pp 21-28

Appendino P, Badini C, Marino F and Tomari A 1991 J. Mater. Sci. \& Eng. A135 275

Doel T J A and Bowen P 1996 Composites A27 655

Gui M C, Wang D B, Wu J -J, Yuan G -J and Gli C $2000 \mathrm{~J}$. Mater. Sci. \& Technol. 16556

Gupta M and Surappa M K 1995 J. Mater. Sci. Letts 141283

Hoskings F M, Portillo F F, Wunderlin R and Mehrabian R 1982 J. Mater. Sci. 17477

Pramila Bai B N, Ramasesh B S and Surappa M K 1992 Wear 157295
Ramesh C S 1988 Preparation and properties of Al-feldspar composites, $\mathrm{ME}$ thesis, Bangalore University, Bangalore

Ramesh C S, Anwar Khan A R, Ravikumar N and Savanprabhu 2005 Int. J. Wear 259602

Ray S 1993 Mater. Sci. 285397

Robi P S, Sharma V M, Kulkarni M D, Prasad R C and Ramakrishnan P 1996 Processing and properties of Al-alloy matrix composites, Proceedings of ADCOMP (Bangalore: Indian Institute of Science) pp 217-225

Sahin Y and Acilar M 2003 Composite A34 709

Salvo L and Surey M 1994 J. Mater. Sci. \& Eng. A177 19

Surappa MK 2003 Metal matrix composites, in Materials research: Current scenario and future projections (eds) $\mathrm{R}$ Chidambaram and S Banerjee (New Delhi: Allied Publishers Pvt Ltd) pp 301-318 